\title{
Standardised Precipitation Valuation of Water Resources Vulnerability to Climate Variability on the Bui Plateau, Northwest Cameroon
}

\author{
Suiven John Paul Tume \\ Green Care Association-Shisong, Kumbo P.O. Box 141, Kumbo, Bui Division, Northwest Cameroon, Cameroon \\ *Corresponding Author: wantume@gmail.com
}

Copyright $(2019$ by authors, all rights reserved. Authors agree that this article remains permanently open access under the terms of the Creative Commons Attribution License 4.0 International License

\begin{abstract}
Sensitivity of water resources to hydro-climatic variations is a key constraint to development. Standardised Precipitation Index (SPI) was employed to assess vulnerability of water resources to climate variability by computing mean annual rainfall for five stations with the least record of 20 years. SPI values in Bui range from -0.1 to -0.45 . These extreme conditions have led to severe water shortages. Water output was collected from Kumbo Water Authority and Camerounais Des Eaux (Jakiri). Population perceptions on changing water levels and reliability were captured through 200 questionnaires administered across six hydrological basins. Results revealed that springs, streams, pipe-borne water, wells/boreholes have reduced significantly. Respondents also perceived that rainfall has become unreliable because of inconsistent onset of first rains and cessation of the wet season. This calls for enhancement of existing water resources and protection of watersheds to ensure sustainability.
\end{abstract}

Keywords Adaptive Strategies, Drainage Basin, Resilience, Water Scarcity

\section{Introduction}

More than 22.8 million people in 48 countries, most of them in Sub-Saharan Africa, (including Cameroon) will face severe water stress by 2025 [1]. Mounting water stress is attributed to climate variability and change, as well as unsustainable competing users. Africa is highly vulnerable to environmental and climate change, making water resources inextricably more vulnerable [2], [3], [4]. Climate affects water resources negatively through decreasing precipitation against a backdrop of rising temperatures [5]. With all these changes, water availability, stability, access and utilisation are becoming uncertain.
This is gradually leading to water insecurity and vulnerability of rural communities of tropical Africa [6]. The impacts of climate variability and change negatively affect livelihood security globally and induce risks and vulnerabilities in sectors such as health, agriculture and food security, water supply and sanitation, industry and other water-using sectors.

Climate variability is likely to increase the frequency of meteorological and agricultural droughts in the tropics by the end of the $21^{\text {st }}$ Century [1], [7]. This is expected to worsen the incidence of short hydrological droughts in these regions. Changes in the frequency of droughts longer than 12 months are more uncertain, because these depend on accumulated precipitation over long periods. There are evidences that surface water and groundwater drought frequency has changed over the last few decades and impacts of drought have increased mostly due to increased water demand [5]. Climate variability and change is also projected to reduce raw water quality, posing risks to drinking water quality even with conventional treatment. The sources of the risks are increased temperature, increases in sediment, nutrient and pollutant loadings due to heavy rainfall, reduced dilution of pollutants during droughts and disruption of treatment facilities during floods [8].

Over the years, many drought indices have been developed. These range from simple indices such as percentage of normal precipitation to more complicated ones like the Palmer Drought Severity Index [8], [9]. Climatologists in the USA concluded that an index needs to be simple, easy to calculate, statistically relevant and meaningful. The understanding that a meteorological drought has different impacts on groundwater, reservoir storage, soil moisture and streamflow led [10], to develop the Standardized Precipitation Index (SPI), which is a powerful and flexible index to calculate. Precipitation is the only required input parameter. It is effective in analysing wet and dry cycles. 
The occurrence of freshwater resources is dictated by many variables, which range from those ordained by nature through anthropogenic influences. The natural variable here is climate, of which one of its elements-rainfall is the main source of water resources recharge in the tropics. Water availability or scarcity brings about development or stress respectively. To understand the present state of water resources on the Bui Plateau, one should have a comprehensive view of standardised precipitation trends order to address the current situation of water shortages. Rainfall is not evenly distributed over space and time throughout the earth's surface. There are deviations from the normal situation, hence, variability, which in turn affects the availability of water resources. Climate variations, coupled with other problems of the natural environment and anthropogenic pressure have led to looming water crisis on the horizon. Potable water is shrinking. Field evidence reveals that during the dry season and even at the heart of the rainy season, water rationing prevails for days and sometimes several weeks. This is a clear indication of depleting underground water resources, triggered by hydro-ecological despoliation of watersheds due to the colonization of headwaters by eucalyptus plantations, over-grazing, unsustainable agriculture and deforestation. These problems need a critical reappraisal to identify more sustainable measures of managing the precious resource. A question, therefore, emerges-what is the pertinence of SPI in assessing vulnerability of water resources?

\section{Methodology}

The Bui Plateau of the Bamenda Highlands Cameroon can be divided into six drainage basins (Figure 1, Table 1). It is situated between latitudes $6^{\circ}-6^{\circ} 20^{\prime \prime} \mathrm{N}$ and longitudes $10^{\circ} 30^{\prime \prime}-10^{\circ} 60^{\prime \prime} \mathrm{E}$. It is a huge orographic plateau along the Cameroon Volcanic Line (CVL) with spectacular landscapes like Mount Oku (3,011m asl) and the MbawTikar Plains $(\approx 900 \mathrm{~m}$ asl). It provides a major watershed for the Niger and Sanaga river systems. Bui has a surface area of $\approx 2,795 \mathrm{~km}^{2}$. Drainage properties of the Bui Plateau are significant in water resources planning. This stems from Horton (1945) who concluded that stream frequency $\left(F_{s}\right)$ indicates the number of streams in an area based on ground and permanent surface waters available in a geographic space. [10] affirmed that an $F_{s}$ value of $1.936 \mathrm{~km} / \mathrm{km}^{2}$ for Bui indicates that for every kilometer, there are nearly two streams that can sustain a community. Streamflow does not respect administrative boundaries. That is why areas that do not have permanent water resources still have pipe-borne water conveyed several kilometers away. Bifurcation ratio $\left(R_{b}\right)$ is a tool to generate data used in calculating $F_{s} . \quad R_{b}$ is also significant in identifying headwaters in the watershed protection process. It gives an inventory of the total number of streams on the landscape which can facilitate the planning process. These values together with the underlying geology, land use and other environmental conditions are very critical in water resources planning and management.

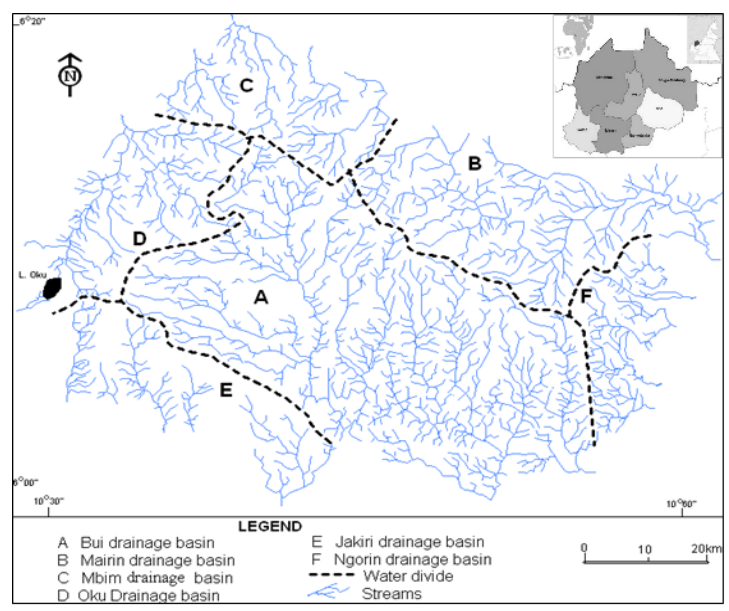

Figure 1. Hydrographic network of Bui Plateau Source: [10]

Table 1. Drainage properties of Bui Plateau

\begin{tabular}{|c|c|c|c|c|c|c|c|c|c|}
\hline \multirow{2}{*}{ Drainage Basin } & \multicolumn{5}{|c|}{ Stream Order } & & & \multicolumn{2}{|c|}{ Linear Properties } \\
\hline & $1^{\text {st }}$ & $2^{\text {nd }}$ & $3^{\text {rd }}$ & $4^{\text {th }}$ & $5^{\text {th }}$ & Total & Basin Area $\left(\mathrm{km}^{2}\right)$ & $* \mathrm{~F}_{\mathrm{s}}\left(\mathrm{km}^{2}\right)$ & $* \hat{\mathrm{R}}_{\mathrm{b}}$ \\
\hline Bui & 400 & 83 & 12 & 2 & 1 & 498 & 888.461 & 0.0011 & 3.7471 \\
\hline Mairin & 150 & 43 & 9 & 1 & 0 & 203 & 567.810 & 0.3575 & 4.3165 \\
\hline Mbim & 71 & 18 & 4 & 0 & 0 & 93.0 & 593.445 & 0.1567 & 2.8148 \\
\hline Oku & 111 & 25 & 6 & 2 & 1 & 145 & 273.324 & 0.5305 & 2.5213 \\
\hline Jakiri-Wainamah & 74 & 19 & 3 & 0 & 0 & 96.0 & 222.150 & 0.4321 & 2.4093 \\
\hline Ngorin & 84 & 22 & 6 & 2 & 0 & 114 & 248.810 & 0.4581 & 2.6211 \\
\hline Total & 890 & 210 & 40 & 7 & 2 & 1,149 & $2,795.00$ & 1.9360 & Mean $=3.0716$ \\
\hline
\end{tabular}

$* \mathrm{~F}_{\mathrm{s}}=$ Stream Frequency $\left(\mathrm{km} / \mathrm{km}^{2}\right),{ }^{*} \hat{\mathrm{R}}_{\mathrm{b}}=$ Mean Bifurcation Ratio. Source: [10] 
To assess water resources vulnerability using SPI, rainfall data was collected as follows: Tatum (59 years), Jakiri (45 years), Shisong (40 years), Mbaw Nso (38 years) and Takui (20 years). SPI is a tool which was developed primarily for defining and monitoring drought. It allows an analyst to determine the rarity of a drought at a given time scale of interest. It can also be used to determine periods of anomalously wet events. Conceptually, SPI is the number of standard deviations by which the precipitation values recorded for a location would differ from the mean over certain periods. In statistical terms, the SPI is equivalent to the Z-score.

$$
Z-\text { score }=x-\frac{\mu}{\delta}
$$

Where: Z-score expresses the $x$ score's distance from the mean $(\mu)$ in standard deviation $(\delta)$ units.

Table 2. Distribution of questionnaires

\begin{tabular}{ccccc}
\hline \multirow{2}{*}{ Drainage Basin } & \multicolumn{2}{c}{ Basin characteristics } & \multicolumn{2}{c}{ Questionnaires } \\
\cline { 2 - 5 } & Streams & Area $\left(\mathrm{km}^{2}\right)$ & Frequency & $\%$ \\
\hline Bui & 498 & 888.461 & 52 & 26.0 \\
Mairin & 203 & 567.81 & 37 & 18.5 \\
Mbim & 93 & 593.445 & 32 & 16.0 \\
Oku & 145 & 273.324 & 31 & 15.5 \\
Jakiri-Wainamah & 96 & 222.15 & 27 & 13.5 \\
Ngorin & 114 & 248.81 & 21 & 10.5 \\
\hline Total & 1,149 & 2,795 & 200 & 100 \\
\hline
\end{tabular}

Source: Fieldwork, 2018

The drought vulnerability for this study is assessed by reconstructing historical occurrence on an 8-months' time scale, beginning from March (onset of wet season) and ending in October (end of wet season). This time-scale is the wet season, where water is relatively more available. Typical dry season (November-February) is not used in assessing SPI for this study because these are normal drought season months. This drought season is when the agro-hydrological system, as well as other components of the natural-human environments are most vulnerable to water scarcity. Two hundred (200) single-object close-ended questionnaires were administered to the population across the drainage basins of the Bui Plateau to capture reliability of water resources during the dry and wet seasons (Table 2).

A 5-point Likert scale for springs, streams, pipe-borne water, wells/boreholes and rainfall was fashioned most unreliable (MU), unreliable (U), reliable (R), more reliable (MR) and most reliable

(MsR). From the responses, frequencies, percentages and anomalies were calculated to assess vulnerability of water resources.

\section{Results and Discussions}

\subsection{Standardised Precipitation Index}

A drought event occurs any time the SPI is continuously negative and reaches an intensity of -1.0 or less (Table 3 ). The drought event ends when the SPI becomes positive. Each drought event, therefore, has a duration defined by its beginning, end and intensity. The positive sum of the SPI for all the months within a drought event can be termed the drought's magnitude. Drought scenarios throughout the Bui Plateau are illustrated (Figures 2-6).

Table 3. Drought probability of recurrence

\begin{tabular}{|c|c|c|c|c|}
\hline $\begin{array}{c}\text { SPI } \\
\text { Value }\end{array}$ & Category & $\begin{array}{c}\text { Probability } \\
(\%)\end{array}$ & $\begin{array}{l}\text { Freq. } \\
\text { years }\end{array}$ & Severity \\
\hline$>2.00$ & Extreme wet & 2.3 & 100 & $\begin{array}{l}1 \text { in } 1 \\
\text { year }\end{array}$ \\
\hline $\begin{array}{c}1.5 \text { to } \\
1.99\end{array}$ & Severely wet & 4.4 & 70 & $\begin{array}{l}1 \text { in } 1.1 \\
\text { years }\end{array}$ \\
\hline $\begin{array}{c}1.00 \text { to } \\
1.49\end{array}$ & Moderately wet & 9.2 & 50 & $\begin{array}{c}1 \text { in } 1.3 \\
\text { years }\end{array}$ \\
\hline $\begin{array}{l}0 \text { to } \\
0.99\end{array}$ & Mildly Wet & 34.1 & 45 & $\begin{array}{c}1 \text { in } 1.5 \\
\text { years }\end{array}$ \\
\hline $\begin{array}{c}-0.1 \text { to } \\
-0.99\end{array}$ & Mild dryness & 34.1 & 33 & $\begin{array}{l}1 \text { in } 3 \\
\text { years }\end{array}$ \\
\hline $\begin{array}{c}-1.00 \text { to } \\
-1.49\end{array}$ & Moderate dryness & 9.2 & 10 & $\begin{array}{l}1 \text { in } 10 \\
\text { years }\end{array}$ \\
\hline $\begin{array}{c}-1.50 \text { to } \\
-1.99\end{array}$ & Severe dryness & 4.4 & 5 & $\begin{array}{l}1 \text { in } 20 \\
\text { years }\end{array}$ \\
\hline$<-2$ & Extreme dryness & 2.3 & 2.5 & $\begin{array}{l}1 \text { in } 50 \\
\text { years }\end{array}$ \\
\hline
\end{tabular}

Source: [11], [8]

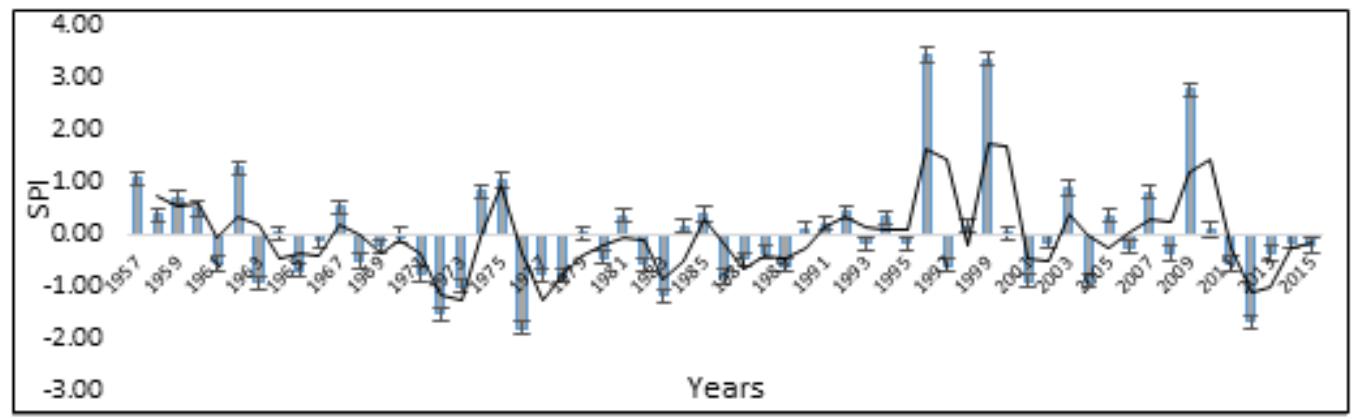

Figure 2. SPI for Tatum, an annual increasing drought trend (1957-2015) 


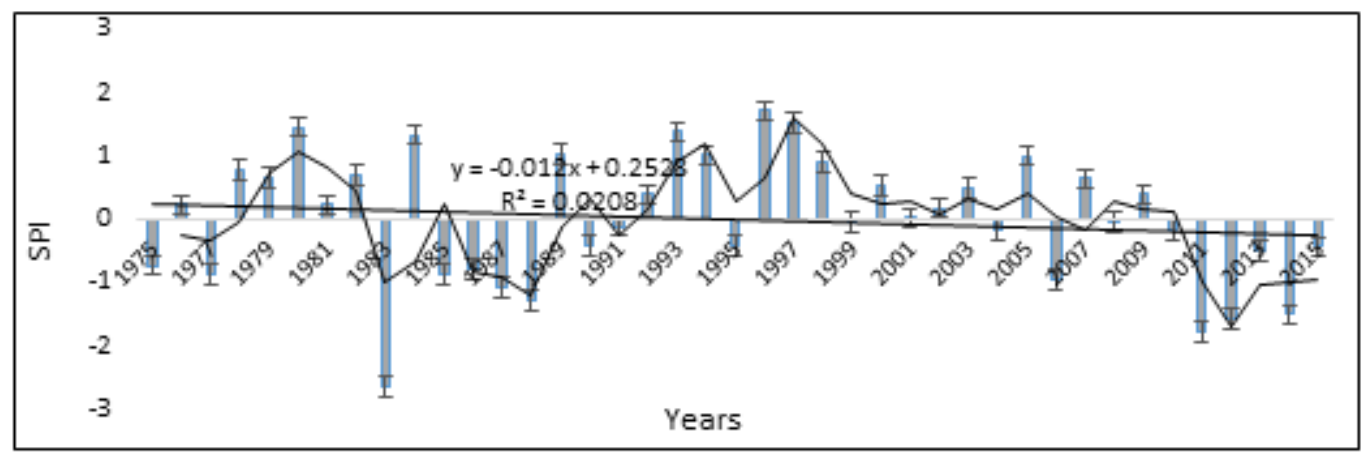

Figure 3. SPI for Shisong, an annual decreasing drought trend (1975-2015)

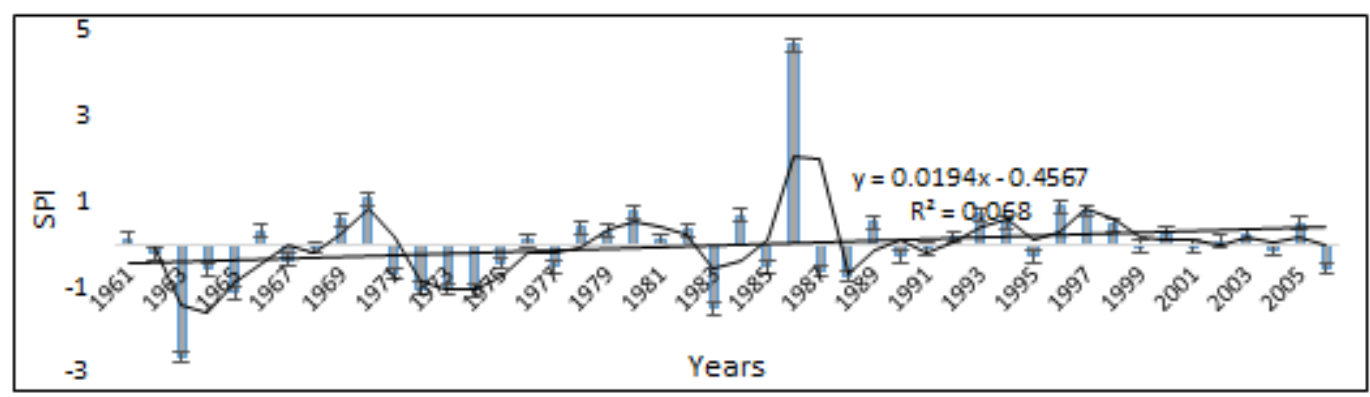

Figure 4. SPI for Jakiri, an annual increasing drought trend (1975-2006)

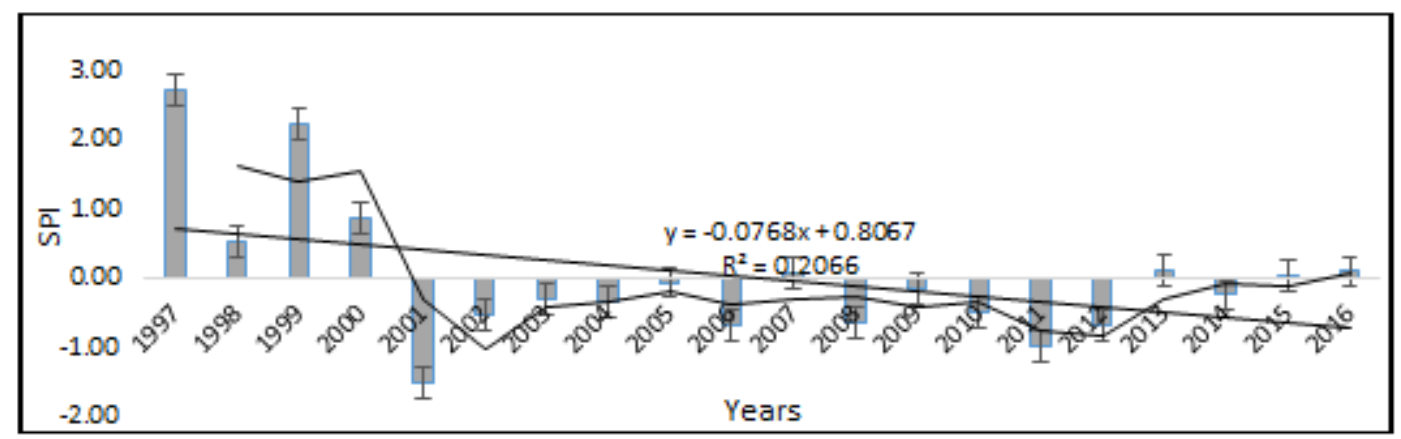

Figure 5. SPI for Takui, an annual decreasing trend (1997-2016)

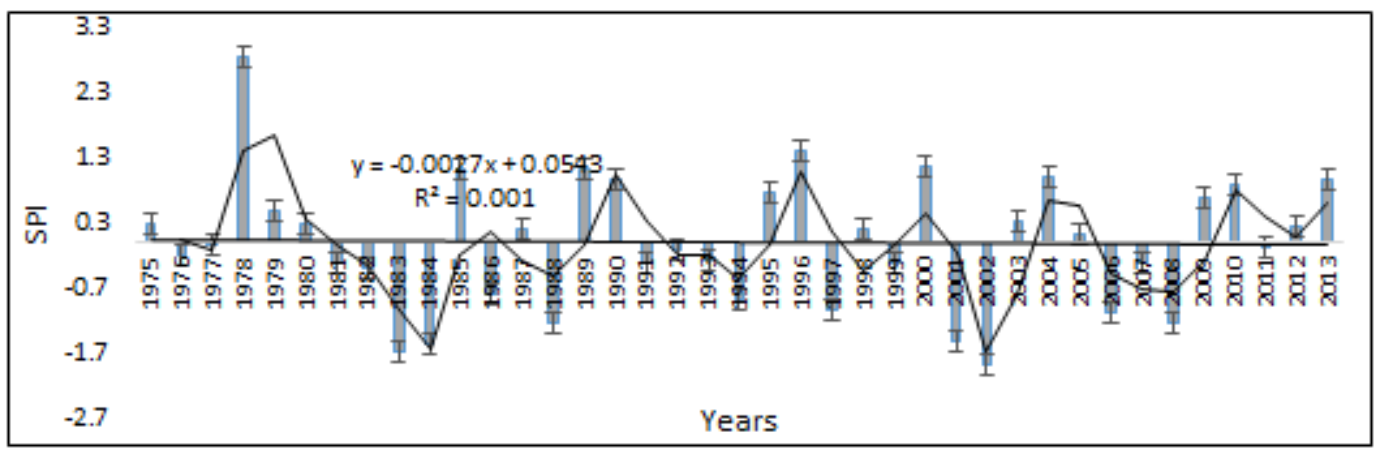

Figure 6. SPI for Mbaw Nso, a slight decreasing trend (1975-2013)

For Tatum, 1957-1966, SPI values ranged from -0.92 to 1.28. There were 2 episodes of moderately wet; 4 episodes of mildly wet and 4 episodes of mild dryness. The decade 1967-1976 had SPI values of -1.78 to 1.05 . This was marked by 1 episode of moderately wet; 2 episodes of mildly wet; 4 episodes of mild dryness; 2 episodes of moderate dryness and 1 episode of severe dryness during the 1976 drought. During the 1977-1986 decade, the SPI 
values ranged from -1.18 to 0.39 . There were 4 episodes of mildly wet; 5 episodes of mild dryness and 1 episode of moderate dryness. From 1987-1996, SPI values were -0.58 to 3.45 .

There was 1 episode of extreme wetness (SPI of 3.45 in 1996); 4 episodes of mildly wet and 5 episodes of mild dryness. The decade 1997-2006, SPI values were $-0.88-3.36$. This was characterised by 1 episode of extreme wetness (SPI of 3.36 in 1999); 5 episodes of mild dryness and 2 episodes of moderate dryness. From 2007-2015, SPI values were -1.66 to -2.79 . There was 1 episode of extreme wetness (SPI of 2.79 in 2009); 2 episodes of mildly wet; 5 episodes of mild dryness and 2 episodes of moderate dryness.

In Shisong, the 1975-1984 decade had SPI values of -2.65 (1983/84 drought) to1.32. This was characterised by 2 episodes of moderately wet; 5 episodes of mildly wet; 2 episodes of mild dryness and 1 episode of extreme dryness during the 1983/84 drought. From 1985-1994, SPI values were -1.29 to 1.37 . There were 3 episodes of moderate wet; 1 mildly wet episode; 4 mild dryness episodes and 1 moderate dryness episode. During the 1995-2004 decade, SPI values were -0.42 to 1.7 . There were 2 severely wet episodes; 5 mild dryness episodes and 3 moderate dryness episodes. From 2005-2015, SPI values were -1.79 to 0.99 . There were 3 mildly wet episodes; 5 mild dryness episodes and 3 moderate dryness episodes.

Jakiri has also witnessed variations in SPI values. From 1961-1970, the values were -2.64 (1963 drought) to 1.07. There was 1 episode of moderate wet conditions; 3 episodes of mild dryness; 1 episode of severe dryness and 1 episode of extreme dryness (during the 1963 drought). From 1971-1980, SPI values were -1.07 to 0.76 . There were 4 episodes of mildly wet; 3 episodes of mild dryness and 3 episodes of moderate dryness. The 1981-1990 decade was marked by SPI values of $-1.49(1983 / 84$ drought) to 4.67 (severely wet conditions in 1986). There was 1 episode of severely were conditions, 3 episodes of mildly wet; 3 episodes of mild dryness and 3 episodes of moderate dryness during the 1997/98 El Nino. 2001-2006 had SPI values of -0.56 to 0.23 . It was characterised by 3 episodes of mildly wet conditions and 3 episodes of mild dryness.

From 1997-2006 in Takui, SPI values were -0.06 to 2.73. There were 2 episodes of extreme wet; 2 episodes of mildly wet; 5 episodes of mild dryness and 1 episodes of severe dryness (1997 El Nino).

From 2007-2016, SPI were -0.99 to 0.1 . This was marked by 4 episodes of mildly wet and 6 episodes of moderate dry conditions.

Mbaw Nso, a lowland agro-ecological basin and major hollow frontier, with an altitude of less than $900 \mathrm{~m}$ asl had 1 episode of extreme wet conditions (1978). The SPI value in 1978 was 2.85 . There were 5 episodes of moderately wet conditions, 13 episodes of mildly wet, 12 episodes of mild dryness, 6 episodes of moderate dryness and 2 episodes of severe dryness (1983-84 droughts). During the 1983-84 droughts, the SPI values ranged from -1.55 to -1.69 .

\subsection{Vulnerability of to Water Resources}

There is the exposure of the hydrological system to droughts. Droughts are assessed in terms of the frequency, magnitude and duration (Table 4). On the Bui Plateau, mild droughts are common all year round, especially during the dry season, when water resources shrink by the drying out of seasonal springs and streams. To be precise, there have been 88 incidents of mild dryness, 23 episodes of moderate dryness, 7 episodes of severe dryness and 2 episodes of extreme dryness between 1957 and 2015. Hazards include any threats to the hydrological system, both sudden shocks and slow increases in stress on the system (due to land degradation and increased rainfall variation). Water resources are very sensitive to current weather and climatic conditions. This sensitivity is determined by environmental and human characteristics that contribute to the hydrological systems responses to exposure. The Bui Plateau is a high energy environment where the topography ranges from $\approx 900-3,000 \mathrm{~m}$ asl. The climate is seasonal, with a rainfall seasonality index of 0.917 (prolonged dry seasons) [10].

Table 4. SPI trends and vulnerability of water resources

\begin{tabular}{|c|c|c|c|c|c|}
\hline \multirow{2}{*}{ Station } & \multicolumn{3}{|c|}{ SPI } & \multirow{2}{*}{$\begin{array}{c}\text { Water resources } \\
\text { vulnerability }\end{array}$} & \multirow{2}{*}{ Level of vulnerability } \\
\hline & $\% \Delta$ & Trend & Drought Cat. & & \\
\hline Jakiri & 0.680 & $\uparrow$ & Mild dryness & Shrinking & Medium \\
\hline Tatum & 0.049 & $\uparrow$ & Mild dryness & Shrinking & High \\
\hline Shisong & 0.208 & $\downarrow$ & Mild dryness & Shrinking & Medium-High \\
\hline Takui & 20.66 & $\downarrow$ & Mild dryness & Shrinking & Low-Medium \\
\hline Mbaw Nso & 0.010 & $\infty$ & Mild dryness & Shrinking & Medium-High \\
\hline
\end{tabular}

$\downarrow$ : decreasing, $\uparrow:$ increasing, $\infty$ : constant (Source: Fieldwork, 2018) 
Watersheds are under the pressure of incompatible land uses (cultivator-grazier conflicts). These pressures on water resources occur against a backdrop of rapid population growth and ailing water infrastructure. These exposures and sensitivities have drastically reduced the resilience of the water system to climate variability. As such, the vulnerability of water resources is medium to high in some communities. Climate variability and change affects the function and operation of existing water infrastructure and management practices [5]. By exposure through dependence on rainfall for recharge of underground and surface waters, the hydrological system of the Bui Plateau is very sensitive to the least changes in weather and climatic conditions. Current water management practices are not robust enough to cope with the impacts of climate variability and change. Observational records provide strong evidence that freshwater resources are vulnerable and will be strongly impacted by climate change, land use and deforestation. In Jakiri, the water output had an increasing trend (1986-2000) (Figure 7), while water storage capacity for Kumbo had a decreasing trend (1975-1990) (Figure 8). Within a period of 16 years, the water storage capacity at Kumbo Water Authority dropped by $\approx 6 \%$. The situation is worsening as water crisis is the order of the day.

Water scarcity has been recurrent throughout the Bui Plateau (Table 3). The duration of the dry season has consistently increased over the years, giving rise to more mild droughts. The trend line on the SPI graph for all the stations combined is negative (Figure 9). The consequences are consistent domestic water scarcity, recurrent cultivator-grazier conflicts at hollow frontiers and pasture inadequacy on rangelands. With the increasingly variable and changing climate, the recurrence of these mild droughts could increase to moderate, severe or even extreme drought scenarios. [12] concluded that climate change affects livestock production and consequently food production due water scarcity. This calls for adequate conventional and indigenous strategies to adapt to these conditions. Field observations reveal that the level of water resources vulnerability is medium to high. If these changes continue, then the Bui Plateau will likely experience very high to extreme levels of water resources vulnerability.

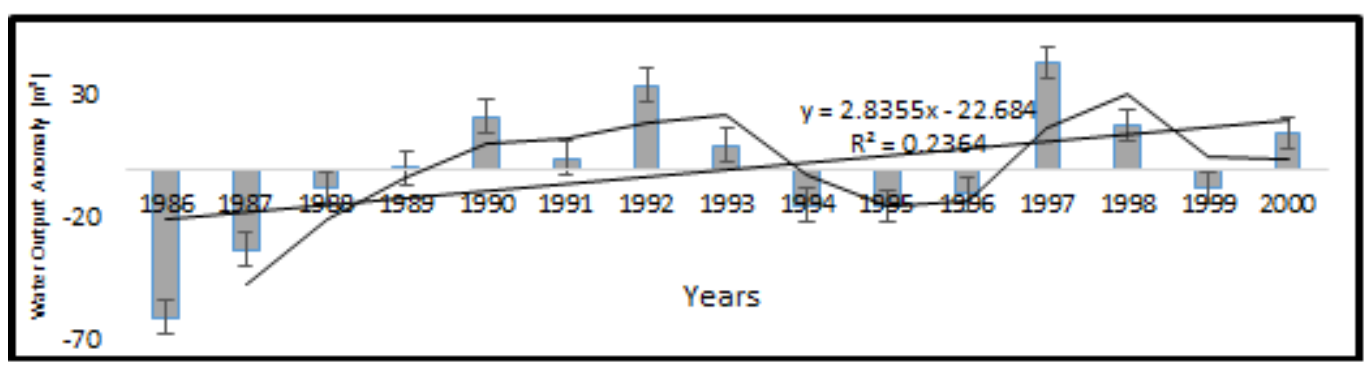

Figure 7. Water output, Camerounais Des Eaux-CDE, (Jakiri) (1986-2000)

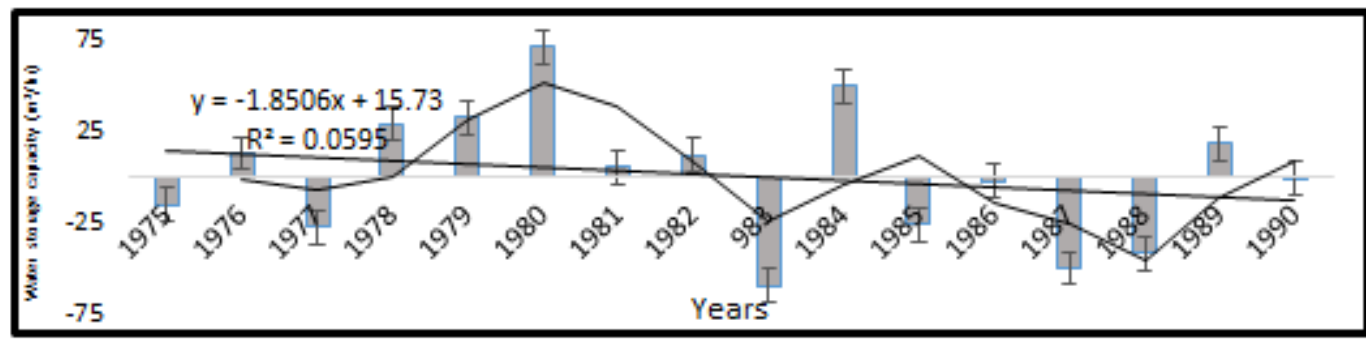

Figure 8. Water storage capacity $\left(\mathrm{m}^{3} / \mathrm{hr}\right)$, Kumbo Water Authority-KWA, (1975-1990)

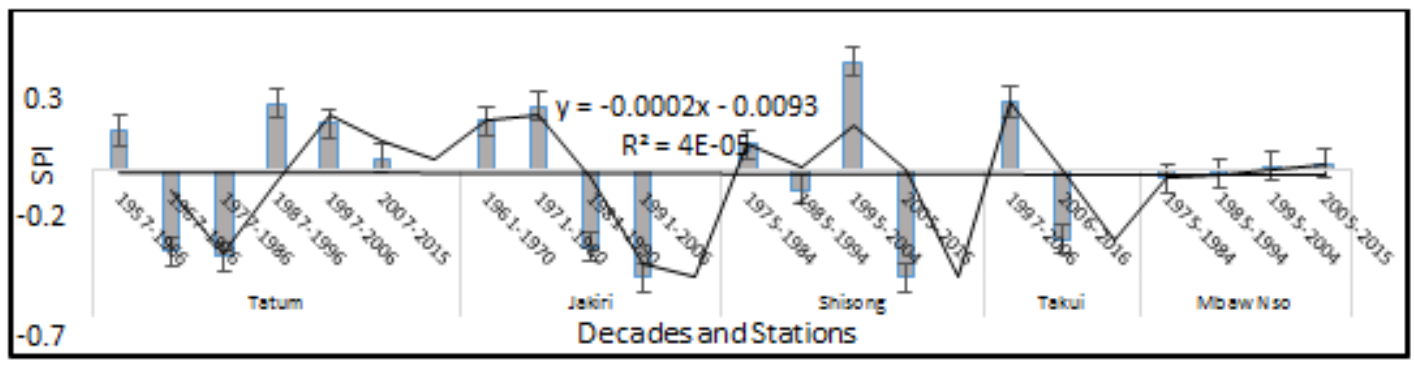

Figure 9. The SPI trend line for stations across the Bui Plateau is below zero (0) 


\subsection{Perceived Changes in Water Levels and Reliability}

The exploitation and management of water resources is a complex process which involves many stakeholders. Bui, seemingly has abundant ground and surface water resources. Seasonal rainfall is still reliable, yet, severe water crisis prevails [10]. This is attributed to 'glocal' environmental changes, especially oscillating climate, incompatible land uses at watersheds and water management lapses [13]. The Bui Plateau has relatively rich aquifers and the residence time is long such that before the onset of the rains in March/April, all the underground reserves would not have been exhausted (Tume, 2008). Water resources management is dependent on many variables including, geology, drainage (stream frequency value of $1.936 \mathrm{~km} / \mathrm{km}^{2}$ ) and land use types [10]. The perceived changes in water resources across Bui are as follows (Table 5):

Springs and streams are the most reliable water resources in all the basins in Bui in the dry and rainy season. Pipe borne water is more reliable during the wet season because groundwater is saturated to supply springs, and eventually communities downstream. Wells and boreholes are reliable in the dry season. The construction of wells and boreholes is relatively a new adaptation across the Bui Plateau. Rainfall is most reliable only during the wet season because the rainy season begins from March/April till October. These perceptions are presented as anomalies (Fig. 10).

Table 5. Perceived changes in water levels and reliability

\begin{tabular}{|c|c|c|c|c|c|c|c|}
\hline \multirow{2}{*}{ Hydrological Basins } & \multirow{2}{*}{ Water Resources } & \multicolumn{5}{|c|}{ Scale of Reliability (\%) } & Seasons \\
\hline & & MU & $\mathrm{U}$ & $\mathrm{R}$ & MR & MsR & D $\quad$ W \\
\hline \multirow{5}{*}{ Bui $\left(888.461 \mathrm{~km}^{2}\right)$} & Springs & 0 & 0 & 20 & 20 & 12 & \\
\hline & Streams & 0 & 0 & 12 & 20 & 20 & \\
\hline & Taps & 6 & 23 & 16 & 6 & 1 & \\
\hline & Wells/boreholes & 8 & 16 & 23 & 3 & 2 & \\
\hline & Rain & 0 & 0 & 31 & 16 & 5 & \\
\hline \multirow{5}{*}{ Mairin $\left(567.81 \mathrm{~km}^{2}\right)$} & Springs & 0 & 0 & 9 & 12 & 16 & \\
\hline & Streams & 3 & 2 & 9 & 9 & 14 & \\
\hline & Taps & 0 & 9 & 5 & 7 & 16 & \\
\hline & Wells/boreholes & 3 & 7 & 9 & 7 & 11 & \\
\hline & Rain & 0 & 0 & 23 & 9 & 5 & \\
\hline \multirow{5}{*}{$\operatorname{Mbim}\left(593.445 \mathrm{~km}^{2}\right)$} & Springs & 0 & 0 & 4 & 8 & 20 & \\
\hline & Streams & 1 & 4 & 5 & 6 & 16 & \\
\hline & Taps & 3 & 3 & 5 & 2 & 19 & \\
\hline & Wells/boreholes & 8 & 3 & 4 & 7 & 10 & \\
\hline & Rain & 0 & 0 & 3 & 4 & 25 & \\
\hline \multirow{5}{*}{ Oku $\left(273.324 \mathrm{~km}^{2}\right)$} & Springs & 3 & 0 & 5 & 7 & 16 & \\
\hline & Streams & 6 & 1 & 4 & 5 & 15 & \\
\hline & Taps & 12 & 6 & 7 & 5 & 1 & \\
\hline & Wells/boreholes & 6 & 7 & 8 & 2 & 8 & \\
\hline & Rain & 0 & 6 & 2 & 6 & 17 & \\
\hline \multirow{5}{*}{ Jakiri-Wainamah $\left(222.15 \mathrm{~km}^{2}\right)$} & Springs & 1 & 6 & 0 & 12 & 8 & \\
\hline & Streams & 1 & 7 & 4 & 12 & 3 & \\
\hline & Taps & 5 & 4 & 6 & 10 & 2 & \\
\hline & Wells/boreholes & 0 & 18 & 5 & 4 & 0 & \\
\hline & Rain & 0 & 0 & 6 & 21 & 0 & \\
\hline \multirow{5}{*}{ Ngorin $(248.81$ km²) } & Springs & 0 & 0 & 0 & 1 & 20 & \\
\hline & Streams & 0 & 0 & 10 & 3 & 8 & \\
\hline & Taps & 16 & 3 & 2 & 0 & 0 & \\
\hline & Wells/boreholes & 20 & 1 & 0 & 0 & 0 & \\
\hline & Rain & 0 & 0 & 0 & 11 & 10 & \\
\hline
\end{tabular}

MU: most unreliable, U: unreliable, R: reliable, MR: more reliable, MsR: most reliable, D: dry season; W: wet season. (Source: Fieldwork, 2017-2018) 


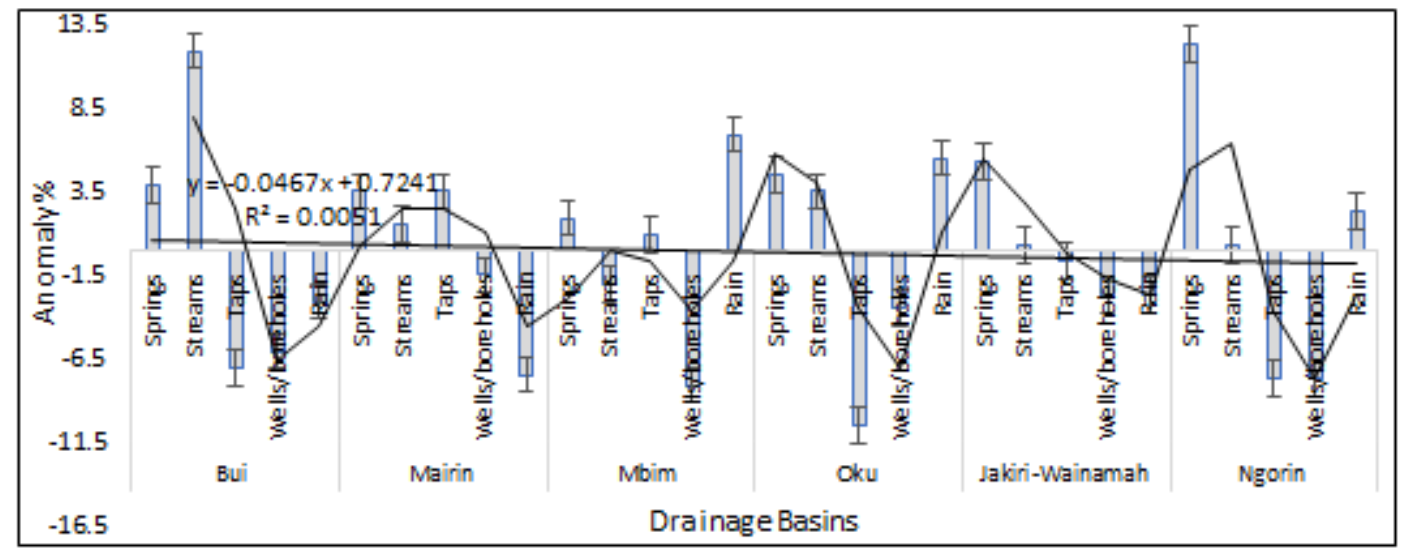

Source: Fieldwork, 2017-2018

Figure 10. Perceived trend anomaly of declining water resources on the Bui Plateau

Respondents perceived that rainfall is still reliable. They are convinced that water supplies all year is because of enough rainfall that recharges groundwater, despite changing environmental and climatic conditions. One of the suitable meteorological indices to assess rainfall reliability is the Coefficient of Variation (CV). In the tropics, an annual $\mathrm{CV}$ of less $20 \%$ is an indicator that rainfall is reliable, while a threshold of more than $20 \%$ indicates that rainfall is unreliable [14].

\subsection{Coping with Water Scarcity}

Rural communities have a long history of responding to climate variability and change, with varying levels of success. These short-term coping strategies can form the basis of successful long-term adaptation strategies [15]. A temporary strategy at the household level is basically water storage in large containers for domestic use. Long-term adaptation can be planned, reactive, autonomous and anticipatory [16]. It includes government policies, NGO programmes and autonomous decisions by communities. Most of the community water supply schemes in the Bamenda Highlands of Cameroon were realised by HELVETAS (Swiss Association for International Co-operation) from the 1960s-1990s. This organisation routinely proposed catchment areas protection for sustainable water production. Two types of catchment areas are distinguished: spring protection, if the water intake is at a spring, or stream bank protection, if water intake is from a stream [17]. A participatory approach is followed, where the local population is trained and empowered to manage their own watershed. In a typical case, the ownership of the catchment area is obtained by a local water management committee (WMC) that employs caretakers to manage the catchment area. The area is clearly demarcated and fenced with barbed wire to keep cattle out. A life fence is planted to create a permanent and sustainable protection of the area against cattle and bush fires. Fire tracing around watershed is also effective in some communities. Indirectly, catchment protection is facilitated by introducing income generating activities for graziers and farmers with the aim to prevent them from entering the catchment areas. The local populations who have been sensitised on this approach are then supposed to manage the catchment area in collaboration with the WMC at their own time and expense. From 1998 to 2004, HELVETAS designed and implemented watershed projects in 44 communities in Bui. This involved the protection of about 60 catchments, covering a surface area of over 1,800ha. Major causes of watershed degradation are the expansion of eucalyptus plantations, unsustainable agricultural activities and grazing. The eucalyptus tree secretes toxins which inhibit the growth of other plant species. A mature eucalyptus tree takes up about 400 litres of water daily and has as such led to the drying up of water in catchment areas [17].

The introduction of indigenous/exotic trees into these areas (Analog Forestry) is a good option for the rehabilitation of these degraded areas. Local and international NGOs like SHUMAS (Strategic Humanitarian Services) and HELVETAS championed watershed protection since the 1990s. Municipal Councils have also been active in watershed protection. For instance, the Kumbo Council made a project proposal to protect some existing water catchments in the municipality [18], [19]. These included Kitiwum, Kikaikelaki, Kai, Meluf, Melim, Mbuluf, Nzenshwai, Njavnyuy and Tadu. The role of the municipal councils is to co-ordinate and assist the various water schemes, by seeking funding and supervising the execution. The inhabitants of these villages are involved in tree planting, fire tracing and construction of dead and live fences [20], [21].

\section{Conclusion and Recommendations}

The Bui Plateau has a wet season that covers a period of eight months and a dry season spell of about four months. This erroneously gives the impression that water is available for most parts of the year. Each year, water 
scarcity continues to be heightened especially during the dry season. Climatic data has proven that the onset of the wet season starts around late March to mid-April. The beginning of rainfall does not mean the abrupt recharge of springs given that the rate of human occupation of watersheds is unprecedented. This partly explains why in spite the coming of the rains in March, water scarcity persists till early June. The first two months of the wet season (March-April) are characterised by erratic and extreme rainfall episodes, increased surface runoff and sediment pollution of water bodies because of enhanced erosion from agricultural and grazing highlands which, at the same time, are the major watersheds. Continuous local climatic variations have affected water supply. This has been seen in the reduced and less reliable nature of stream flow whose magnitude and trend depend strongly on local climatic, hydrological and ecological conditions. Although there is scarcity of data to scientifically ascertain this assumption, field observations suggest that the gradual changes in rainfall patterns, increased evapotranspiration and alterations of the soil properties are gradually displacing the dominant sandwiched savannah/forest ecological boundary with increasing drier conditions over time. These have negatively affected the supply of water. This calls for vigorous conventional and indigenous adaptations. A sustainable adaptation strategy is through watershed management. The management of water resources is a multi-stakeholder adventure with clearly defined interconnectedness for efficiency and effectiveness. The World Commission on the Environment and Development [22], [23] warned in the final report, Our Common Future, that water supplies were overused in many parts of the world more than they are replenished. Thus, the management of water resources on the Bui Plateau has its intricate challenges which need to be reappraised to ensure a sustainable future for generations to come. While noting that the present generation is already borrowing from the future, the following recommendations are proposed:

\subsection{Donor Organisations}

These are mainly Non-Governmental Organisations whose mission is to improve rural livelihoods through the provision of water and improving the state of the natural environment. Support should not end in planning and implementing water projects. With the realisation of each project, these donor organisations should manage the scheme for a transitional period about two years during which they can build the capacity of indigenes to run the schemes efficiently. These donor organisations should also design sustainable watershed practices such that the exploitation of one resource at the catchment area should not affect the quantity and quality of water. Some of these measures could include sustainable agriculture like agroforestry and the practice of apiculture at watersheds.

\subsection{Local Water Management Boards}

The management of community water resources is entrusted into the hands of these committees. Rules and regulations should be clearly defined and implemented scrupulously. These bodies should also have legal instruments to sanction delinquent executive members especially the misappropriation and the management of funds geared towards the expansion of water networks and maintenance. The caretakers should be recognised and given due financial remunerations as their role in the management of these schemes need not be overemphasised. The communities should be enlightened on sustainable water uses to avoid wastage. Sensitisation should be recurrent on the importance of annual financial contributions for maintenance, manual work when need arises and hygienic conditions around domestic and public taps. The community should avoid such activities like laundry at public taps and the unethical practice of overflowing water containers such that water spills over to the ground. This is wastage. Community members should also take upon themselves to plant environmentally friendly tree species around watersheds.

\subsection{Water Management Authorities}

These authorities should establish consistent data bases for variables like seasonal water discharge and the amount distributed to consumers. They should also establish a data base for climatic elements that affect water resources: rainfall, temperature, evaporation and humidity around their watersheds to ascertain how change in these elements is affecting water resources in this era of 'glocal' environmental changes. These authorities should also embark on sustainable watershed practices like demarcation, afforestation and re-afforestation with environmentally friendly tree species and resettle displaced communities around watersheds to avert conflicting land uses. Municipal councils should have a clear vision and mission in their plans of action for natural resource management, especially water resources. They should act as supervisory bodies of existing water schemes and should put in more financial resources for a proper functioning of these schemes. Capacity building in the areas of budgeting for water management and watershed protection should be sustainable. Legal action on defaulters around watersheds and delinquent water manage ment committees should be enforced. In all, these stakeholders should always adopt an eclectic approach in water resources management.

\section{REFERENCES}

[1] Lükenga, W., 2015. Water Resource Management. Book Boon, London, 18-19. 
[2] Arnell, N.W., 2006a. Global Impacts of Abrupt Climate Change. An Initial Assessment. Working Paper 99, Tyndall Centre for Climate Change Research, University of East Anglia, Norwich, 37.

[3] Arnell, N.W., 2006b. Climate Change and Water Resources. A Global Perspective. Avoiding Dangerous Climate Change. Cambridge University Press, Cambridge, 167-175.

[4] Frederick, K.D. \& Major, D.C., 2004. Climate Change and Water Resources. In Toman, M.A. \& Sohngen, B. 2004. Climate Change. The International Library of Environmental Economics and Policy, Ashgate Publishing Company, Burlington, 41-57.

[5] Bates, B.C., Z.W. Kundzewicz, S. Wu \& J.P. Palutikof, (Eds.) 2008. Climate Change and Water. Technical Paper of the Intergovernmental Panel on Climate Change, IPCC Secretariat, Bonn, 210.

[6] Ababaei, B., Sohrabi, T., \& Mirzaei, F., 2014. Developing and Application of a Planning Support System to Assess strategies related to Land and Water Resources for Adapting to Climate Change. Climate Risk Management, Vol. 6, 39-50.

[7] Ericksen, P., Thornton, P., Notenbaert, A., Cramer, L., Jones, P., \& Herrero, M., 2011. Mapping Hotspots of Climate Change and Food Insecurity in the Global Tropics. CCAFS Report CGIAR Research Program on Climate Change, Agriculture and Food Security (CCAFS), Copenhagen, No 5, 50 .

[8] World Meteorological Organisation-WMO, 2012. Standardized Precipitation Index User Guide. WMO (1090), Geneva, 24

[9] World Meteorological Organization-WMO \& Global Water Partnership-GWP, 2016. Handbook of Drought Indicators and Indices. Integrated Drought Management Programme (IDMP), Integrated Drought Management Tools and Guidelines Series 2, Geneva, 1-45.

[10] Tume, S.J.P., 2008. Rainfall Variability and Implications on Water Resources Management. The Case of Bui Division, Northwest Province of Cameroon. MSc Thesis, Department of Geography, University of Buea, 210.

[11] McKee, T.B., Doesken, N.J., Kleist, J., 1993. The Relationship of Drought Frequency and Duration to Time Scales. Proceedings of the Eighth Conference on Applied Climatology. American Meteorological Society, Boston, 179-184.

[12] Rojas-Downing, M.M., Nejahashemi, A.P., Harriga, T., \& Woznick, S.A., 2017. Climate Change and Livestock. Impacts, Adaptation and Mitigation. Climate Risk Management, (16), 145-163.

[13] Tume, S.J.P., 2009. Incompatible Land Uses: A Source of Conflict at the Watershed Scale on the Bui Plateau, Northwest Region, Cameroon. Proceedings of Postgraduate Seminar II, Faculty of Social and Management Sciences, University of Buea. January 2009, 38-56.

[14] Ayoade, J.O., 1998. Introduction to Climatology for the Tropics. Fourth edition, Spectrum Books, Ltd., Ibadan.

[15] Organisation for Economic Co-operation and Development-OECD, 2009. Integrating Climate Change
Adaptation into Development Co-operation, Policy Guidance. OECD, Paris, 193.

[16] Intergovernmental Panel on Climate Change-IPCC, 2007. Climate Change 2007. Impacts, Adaptation and Vulnerability. Contribution of Working Group II to the Fourth Assessment Report of the Intergovernmental Panel on Climate Change. Cambridge University Press, Cambridge UK, 976.

[17] Waarde van der, J. J., 2004. Helvetas Cameroon Experiences in Catchment Protection Activities. Helvetas Cameroon, Swiss Association for International Co-operation, 24.

[18] Wirsiy, E. F., Youndjie, K. G., Atanga, W. \& Fru, M., 2006. Feasibility Study on the Introduction of Analog Forestry in Bui Division, Northwest Province of Cameroon. Report on Community Consultation. CENDEP, Victoria.

[19] Lingondo P .E., F. Y. Lawir, P. Ndzefemmegho, E. Fonba, G. A. Tanda, E. F. Jivirka, G. Njodzeka, P. B. Ngah \& M. Fonyuy, 2008. Baseline Socio-Economic Report for Mvem Cluster, Kitiwum and Mbiame in Bui Division. CENDEP, Victoria.

[20] Centre for Nursery Development and Eru Propagation-CENDEP, 2008. First Project Review and Planning Workshop (February 1, 2008-July 31, 2008), CENDEP, Victoria.

[21] Centre for Nursery Development and Eru Propagation-CENDEP, 2009. Second Project Review and Planning Workshop (August 1, 2008-January 31, 2009), CENDEP, Victoria.

[22] World Commission on the Environment and Development, 1992. Our Common Future. Rio de Janeiro.

[23] United Nations Environment Programme-UNEP, 2010 Making the Case for Ecosystem based Adaptation. Building Resilience to Climate Change. UNEP, Nairobi, 11. 